\title{
Life cycle thinking in the aluminium industry
}

\author{
Patrick de Schrynmakers
}

Received: 27 June 2008 / Accepted: 13 December 2008 /Published online: 24 March 2009

(C) Springer-Verlag 2009

\section{Introduction}

Major characteristics of our early twenty-first century include phenomena such as globalisation and intense demographic growth coupled with increasing scarcity of resources. As one of the consequences, end-user demands have changed. Such trends challenge the world community. Traditional market drivers such as price and technical performance are nowadays complemented by environmental and other sustainability aspects. There is a need for resource-efficient products with a high environmental performance not only related to the production processes but also taking into consideration the entire life cycle. This requires sound environmental information.

In recent years, the influence of consumption as a driver of environmental effects has been increasingly acknowledged, triggering the development of product-related initiatives like:

- Integrated product policies

- Initiatives on the sustainable use of natural resources

- Prevention and recycling of waste

- Eco-labelling

- Eco-design requirements for energy-using products

- Design for the environment

- Initiatives on sustainable consumption and production

Responsible editor: Gerald Rebitzer and Jörg Schäfer

Int J Life Cycle Assess, Special Issue "Life Cycle Performance of Aluminium Applications"

P. de Schrynmakers $(\square)$

European Aluminium Association,

Avenue de Broqueville 12,

1150 Brussels, Belgium

e-mail: schrynmakers@eaa.be
With the introduction of voluntary and mandatory measures and instruments, those businesses that were pressed to extend the producer and product responsibility to the entire value chain started to live up to the challenge.

The aluminium industry engaged very early in a stakeholder dialogue. The result of these stakeholder consultations clearly indicated the need to expand the producer and product responsibility to include upstream and downstream impacts. To address this effectively, life cycle thinking is essential. Life cycle thinking is a fundamental prerequisite towards understanding impact mechanisms along value chains in complex product or production systems. It is the indispensable approach to support sustainable development. Accordingly, the following goals were defined in the general framework of Sustainability for the aluminium industry:

- to meet the needs of modern society and create value by offering (more) sustainable aluminium products with unique properties

- to create the opportunity to reduce environmental impacts through the substitution of other products by aluminium products; simultaneously, to reduce the environmental impact of our production processes and of our products throughout their life cycle

- to address our social responsibilities towards employees, customers, suppliers, local communities and society in general

- to achieve continuous progress through regular indicator-based reporting and exchange of best practices

- to encourage companies to work along the lines of international agreements like the UN Global Compact.

All these objectives rely on the basic principles of life cycle thinking. The aluminium industry, convinced of the relevance and value of this approach for some consider- 
able time, has been applying life cycle assessment (LCA) methods to product development with a view to increasing the knowledge about products and processes, finding ideas for innovation and identifying potential for improvement.

The gathering of life cycle indicator data kicked off in 1992 to cover major European aluminium producers and manufacturers, and very soon, the first Ecological Profile Report was published (EAA 1996). Since then, regular updates carried out in a sound and transparent manner have made this report into a reliable, state-of-the-art database (EAA 2000, 2005, 2008).

A major sustainability objective of the aluminium industry is to enhance environmental performance through all stages of the life cycle of aluminium products. A thorough understanding of the different parts of the life cycle of a product is a prerequisite in order to improve technologies and enhance the environmental performance of products. Therefore, an adequate tool is needed to describe links and interdependencies in the life cycle so as to be sure that an isolated improvement in one step of the life cycle does not have a detrimental impact on the performance throughout the entire cycle. This is the essence of what we call life cycle thinking, an approach aligned with life cycle assessment according to ISO 14040/44 standards (ISO 2006a, b).

The aluminium industry has itself been supporting the definition of the ISO LCA Standards since the start and has significantly contributed to the development of a stable and robust methodology offering the proper basis for life cycle thinking in today's environment-focussed context.

\section{The life cycle of aluminium products}

The production of primary aluminium consists of three major steps: bauxite mining, alumina production and electrolysis, more commonly known as smelting. The primary production of aluminium is characterised by its significant energy demand. Once produced, aluminium metal can undergo various fabrication processes: rolling, extrusion and casting. The rolled, extruded and cast products are then further processed and finally used in different applications ranging from transport and automotive through building and construction to packaging, machinery and many others.

Aluminium's light weight is an advantageous feature extensively exploited in the transport sector. Not only does the use of aluminium enable a reduction of energy consumption and avoidance of $\mathrm{CO}_{2}$ emissions throughout the use phase of a transport system but its light-weighting properties were also a key in the development of the aerospace industry.
Another strength of aluminium is its high durability, which makes it a material of choice for the building sector by significantly reducing maintenance requirements throughout the use phase. Further properties and features even enable aluminium products to cater for more specific needs within and beyond building applications: good electrical conductivity in wire and cables or high reflectivity in solar applications make aluminium a premium contributor to energy efficiency and energy production from renewable sources.

Aluminium also boasts outstanding sealing properties, very much praised by the packaging sector for ensuring high and lasting quality to packaged goods, especially foods and beverages. Very thin foil or metallisation applications have been developed to provide maximum functionality with minimum use of resources. Packaging products not only help to conserve the goods and their aromas but also reduces the spoilage rate and prevents the tampering of the product in the package.

Another important sustainability attribute of aluminium is its recyclability, which is a clear asset for many products. Aluminium has been recycled since the metal first began to be used commercially. It is estimated that about $75 \%$ of the primary aluminium ever produced is still in use, demonstrating that aluminium recycling is a reality and ensures aluminium metal conservation (International Aluminium Institute, European Aluminium Association, Organisation of European Aluminium Refiners and Remelters 2006). Good commercial reasons have always made recycling worthwhile. The high intrinsic value of aluminium scrap makes recycling economically attractive. Using today's technology, aluminium and its alloys are re-melted and reused without any loss in quality. Besides, aluminium recycling requires much less energy than the production of primary aluminium from its ore. Thus, recycling is a cornerstone of the sustainability of most aluminium products, saving both raw materials and energy while also reducing demands on landfill sites. And where aluminium cannot be recycled efficiently, e.g. in certain packaging applications, it is often incinerated, allowing energy to be generated by the combustion of the aluminium foil.

\section{Key aspects for life cycle analysis on aluminium products}

As life cycle thinking and LCA methodologies have become more widespread, the importance of standards to ensure the quality and acceptance of the results has increased, and respecting the fundamental elements of the ISO 14040/44 (2006a, b) standards has proved capital when assessing aluminium products. Precision is paramount in a broad range of parameters, none of which should be 
overlooked. Utmost care is required to identify what is comparable, based on what functional unit, within what system boundaries, in what sensitivity range, on what impact categories, and of course on what exact data.

If products are compared on the basis of LCA results, the functional unit for the comparison has to be carefully selected and precisely defined. It is for instance not possible to compare products on the sole basis of the mass of the applied material. Although such an approach is not in line with the LCA methodology, it is often used in public debates, in particular when simplified LCAs are requested. It cannot be stressed enough that it is essential to compare the same functionality and the corresponding different reference flows.

If the system boundaries of a product are defined, it is clear that a full understanding of life cycle assessment calls for the inclusion of the entire life cycle of a product. In particular, in the case of aluminium products, it is a must that all the different phases of the lifetime of a product be considered, as many phases offer relative savings with respect to environmental loads. The use phase for instance allows - in particular for moving parts-a potential for the reduction of environmental loads due to the light weight of aluminium components. Going even beyond transport applications, this consideration is not any less relevant in packaging solutions should the packages be moved in order to be distributed.

Going further along the lines of scientific thoroughness: In buildings, it is often difficult to define an exact maintenance scenario for a product. Likewise, in the automotive sector, it is hard to evaluate the exact use of a car during its lifetime. To face such challenges to predictability, the ISO standard recommends varying the parameters to gain a clear picture of their influence on the result. Such a sensitivity analysis also improves the credibility of an LCA study and is, therefore, a very significant element, unfortunately too often overlooked in studies. Commonly encountered assumptions for sensitivity analysis include:

- service life of a building product

- maintenance intervals of products

- lifespan driving distance of a car

- distribution distance of packed products

- load of electrical systems

- trippage rate of refillable packing systems

- recycling rates if no recycling system is in place

Thinking in life cycle terms, recycling is obviously another important part of any LCA on aluminium products. In this respect, the aluminium industry clearly supports the "Declaration by the Metals Industry on Recycling Principles", which recommends the end-of-life recycling approach and encourages manufacturers, policy-makers and other decision-makers to evaluate and consider the real performance of products to improve their design and to perfect their management, including their disposal and recycling (Atherton 2007).

Moving on from the object to the effects, the choice of the considered impact categories also significantly affects the result of an LCA. If only one impact category is chosen, e.g. Climate Change, a statement can only be made on this aspect, meaning that no overall assessment of the environmental performance is possible. Therefore, a clear statement on the restricted value of such a study must be made when defining the goal. Nevertheless, an increasing number of studies carried out today disregard this stringent requirement. Climate change is of course an important environmental aspect, but to focus on this indicator alone is misleading. Therefore, in order to obtain a clear and environmental panorama of a product, a well-defined and selected set of indicators is needed.

Finally, data are the core of any LCA. The aluminium industry offers a set of data which refer to European average figures on all of the above-listed production processes. These data sets are periodically updated and reviewed by an external expert, thus, offering a high degree of reliability and transparency (EAA 1996, 2000, 2005, 2008). They are certainly the most reliable datasets available for carrying out LCAs on aluminium products. Yet, it should always be borne in mind that only comparable can be compared, and comparison, therefore, relies on common understanding, i.e. harmonisation, especially on four aspects:

- the datasets used need to be equally fit for the specific purpose

- all should reflect the current state of the art

- they need to have the same level of detail

- clear rules should apply to cut off criteria, i.e. it has to be clearly defined which data can be neglected due to a low relevance.

\section{Conclusions}

Striving for sustainability can only be envisaged if we are able to assess the social, economic and environmental impacts of our consumption patterns and are committed to continuous improvement. Important elements for these assessments are the performance features of products and services. Life cycle thinking has to be the backbone of these assessments to ensure that what is pursued is overall improvement, that issues are not simply transferred along the value chain or to other media and that trade-offs are highlighted and evaluated. This is why sustainabilityrelated decision-making both by businesses and regulators should be underpinned by life cycle thinking. 
It is essential that the highest standards be applied as well to the consideration of the complete product or service systems as to the reliability, consistency and transparency of the applied data. For any aluminium products, it is a prerequisite to include the entire life cycle starting from bauxite mining, taking the use phase into consideration and ending with the recycling of the end-oflife product.

The aluminium industry has demonstrated its determination in pursuing its commitment to apply life cycle thinking consistently and to address the most significant impacts along its value chain. In 2002, the European Aluminium Association and its member companies embarked on a pioneering journey towards measuring sustainability. Through the Aluminium for Future Generations programme, and together with its partners-the Wuppertal Institute for Climate, Environment \& Energy, the Versailles University and an additional peer group of internal and external stakeholders-the European Aluminium Industry has developed 34 measurable Sustainable Development Indicators to be systematically tracked and transparently reported.

\section{References}

Atherton J (2007) Declaration by the Metals Industry on Recycling Principles. Int J Life Cycle Assess 12(1):59-60

EAA-European Aluminium Association (1996) Ecological profile report for the European Aluminium Industry. EAA, Brussels

EAA-European Aluminium Association (2000) Environmental profile report for the European Aluminium Industry. EAA, Brussels

EAA-European Aluminium Association (2005) Environmental profile report for the European Aluminium Industry. Primary Aluminium update-year 2002; Semi-finished aluminium products and process scrap recycling Update-year 2002; Aluminium recycling in LCA. EAA, Brussels

EAA-European Aluminium Association (2008) Environmental profile report for the European Aluminium Industry, Life cycle inventory data for aluminium production and transformation processes in Europe. EAA, Brussels, 72-12 pp

ISO-International Standard Organisation (2006a) Environmental management-life cycle assessment: Principles and framework. ISO 14040

ISO-International Standard Organisation (2006b) Environmental management-life cycle assessment: Requirements and Guidelines. ISO 14044

International Aluminium Institute, European Aluminium Association, Organization of European Aluminium Refiners and Remelters (2006) Global aluminium recycling: A cornerstone of sustainable development. Brussels 